\title{
Experimental study on some properties of a low-carbon cement
}

\author{
Niu quanlin ${ }^{1, a^{*}}$ zhang rui $^{2, b}$ \\ ${ }^{1}$ school of material science and engineering, Shandong university of technology, Zibo, Shandong \\ 255049, P.R .China \\ ${ }^{2}$ Library of shandong university of technology, Zibo, Shandong 255049, P.R .China \\ aniuql00@sdut.edu.cn
}

Keywords: concrete; low-carbon cement ; strength

Abstract: a low-carbon cement (LCC) consists of $10 \%$ of cement clinker and $90 \%$ of industrial wastes was prepared, properties of the LCC such as setting time, soundness, consistency, as well as the compressive and flexural strength were examined. It is shown that early strength of the cement was slightly lower, but final strength is higher than the ordinary Portland cement (P.O42.5).

\section{Introduction}

Concrete blended with portland cement and aggregates is the most widely used material in the world, but the manufacturing of portland cement clinker was accompanied with large amount of energy consumption, and $\mathrm{CO}_{2}$ emission of clinker production accounts for $5 \%$ of the total global anthropogenic $\mathrm{CO}_{2}$ emission [1]. For better energy-conservation and pollutants-control, research on low-carbon cement with higher dosage of industrial wastes is getting more and more important, especially in developing countries where large scale of infrastructural construction is ongoing.

One of the low-carbon cement is supersulphated cement (SSC) invented by German Professor H. Kühl [2]. With less than 5\% of clinker and over $95 \%$ of industrial wastes such as slag and gypsum, this cement decreases energy consumption and $\mathrm{CO}_{2}$ emission by over $90 \%$ compared with ordinary portland cement, In the meantime, some properties of the cement were also attractive.

The small percentage (3-5\%) of lime or clinker added releases much less hydration heat, $15 \%$ of gypsum and over $75 \%$ of slag powder ensure large quantity of ettringite formation and expansion of the cement and concrete in long run, both of the properties are beneficial for volume stability of mass concrete.

As the initial setting time of the product is long enough, it is quite suitable for the cement stabilized aggregate mixture; with little alkaline and free $\mathrm{Ca}(\mathrm{OH})_{2}$, the alkaline aggregate reaction and sulfate attack are also minimized; high slag dosage also provide excellent anti-permeability which is very important for the construction of oceanic concrete engineering.

However, the very low content of clinker brings carbonation problem, so in this paper, a cement with clinker content as high as $10 \%$, and $75 \%$ of slag and fly ash, $15 \%$ of fluorogypsum was prepared, properties such as normal consistency, setting time, soundness and mortar strength were examined according to china national standard GB1346-2001 and GB175-2008.

\section{Materials}

Portland cement clinker, granulated blast furnace slag and fluorogypsum were employed in the experiment, cement and fluorogypsum were ground to surface area of $350 \mathrm{~m}^{2} / \mathrm{kg}$, slag was ground to $380 \mathrm{~m}^{2} / \mathrm{kg}$ individually, fly ash was commercial class II product.

Chemical composition of the materials was shown in Table 1.

It is seen in table 1 that the slag powder has high amount of $\mathrm{Al}_{2} \mathrm{O}_{3}$ and $\mathrm{CaO}$. As content of $\mathrm{Al}_{2} \mathrm{O}_{3}$ and $\mathrm{CaO}$ in slag determines its reactivity, the slag, with quality factor of 2.00 is high reactive. 
Table .1 Composition of the cement and admixtures

\begin{tabular}{cccccccccccc}
\hline & \multicolumn{10}{c}{ Composition [wt \%] } \\
\cline { 2 - 12 } Materials & $\mathrm{SiO}_{2}$ & $\mathrm{Al}_{2} \mathrm{O}_{3}$ & $\mathrm{Fe}_{2} \mathrm{O}_{3}$ & $\mathrm{CaO}$ & $\mathrm{MgO}$ & $\mathrm{SO}_{3}$ & $\mathrm{~K}_{2} \mathrm{O}$ & $\mathrm{Na}_{2} \mathrm{O}$ & $\mathrm{LOI}$ & $\mathrm{f}-\mathrm{CaO}$ & $\begin{array}{c}\text { Quality } \\
\text { factor }\end{array}$ \\
\hline P.O 42.5 & 21.10 & 5.23 & 3.37 & 61.72 & 2.26 & 1.88 & 0.72 & 0.40 & 2.55 & 0.36 & $/$ \\
Slag & 31.41 & 16.28 & 1.25 & 38.57 & 8.25 & 0.62 & $/$ & $/$ & 1.33 & 2.00 \\
Fly ash & 41.31 & 25.99 & 7.82 & 3.32 & 1.64 & 2.64 & $/$ & $/$ & 10.85 & $/$ \\
gypsum & $/$ & 0.44 & $/$ & 40.71 & $/$ & 56.64 & $/$ & $/$ & 0.25 & $/$ \\
\hline
\end{tabular}

\section{Experimental}

The low-carbon cement was prepared with $10 \%$ of the ground clinker, $90 \%$ of industrial wastes, namely slag, fly ash and fluorogypsum. Mix proportion of the cement was shown in table 2, properties of the mix, including setting time, soundness, consistency and mortar strength were examined according to chinese national standard GB1346-2001 and GB175-2008.

Table 2 mix proportion (wt\%) and compressive/flexural strength of supersulfated cement [MPa]

\begin{tabular}{ccccccccc}
\hline \hline & clinker & slag & Fly ash & fluorogypsum & $3 \mathrm{~d}$ & $7 \mathrm{~d}$ & $28 \mathrm{~d}$ & $56 \mathrm{~d}$ \\
\hline \hline P.O 42.5 & 80 & 10 & 5 & 5 & $28.7 / 4.65$ & $35.5 / 7.10$ & $52.3 / 9.51$ & $55.7 / 10.2$ \\
\hline SSC1 & 10 & 55 & 20 & 15 & $16.7 / 4.2$ & $30.3 / 6.33$ & $43.5 / 8.5$ & $52.5 / 9.3$ \\
SSC 2 & 10 & 65 & 10 & 15 & $18.8 / 4.5$ & $32.4 / 6.40$ & $47.2 / 9.0$ & $55.2 / 9.9$ \\
SSC 3 & 10 & 75 & 0 & 15 & $22.2 / 4.7$ & $35.0 / 7.6$ & $53.5 / 9.9$ & $63.1 / 11.4$
\end{tabular}

As the strength of the cement with high percentage of slag powder was much affected by the alkalinity of the paste solution, $\mathrm{pH}$ value of SSC2 paste was monitored as well.

The cement (10\% clinker+65\% slag+10\% fly ash $+15 \%$ fluorogypsum) was blended with water, with water/cement ratio is $2: 1$, solution of the hydrated cement was vacuum extracted from the paste and measured by $\mathrm{pH}$ value monitor.

Mechanism of hydration involved was also analyzed with SEM analysis.

\section{Result and discussion}

Physical properties of the supersulphated cement. Consistency, soundness and setting time of the cement were shown in table 3, strength of the mortars was shown in table 2 above.

Table 3 Physical properties of cement

\begin{tabular}{ccccc}
\hline \hline Cement & Consistency ( \% ) & Initial setting & Final setting & soundness \\
\hline \hline SSC 1 & 23.6 & $5: 15$ & $7: 10$ & Fine \\
SSC 2 & 24.3 & $4: 45$ & $6: 35$ & Fine \\
\hline SSC 3 & 24.8 & $4: 35$ & $5: 50$ & Fine \\
\hline \hline P.O42.5 & 28.8 & $2: 40$ & $4: 20$ & Fine \\
\hline \hline
\end{tabular}

It is seen in table 3 that the initial setting time of the supersulphated cement were longer than ordinary portland cement by about 2-3 hours, while final setting delayed by 2-3 hours for SSC 1 and SSC 2, the final setting of SSC 3 with no fly ash added is a little quicker.

As the clinker content is very low, there is little hydration at early age, and both initial and final setting were delayed. 
Soundness of the three supersulphated cement was fine in spite of the high $\mathrm{SO}_{3}$ content, this is attributable to the low $\mathrm{pH}$ value of the hydration environment. In a low $\mathrm{pH}$ value environment $(\mathrm{pH}=10.8-12.5)$, ettringite ( $\mathrm{AFt})$ is formed through dissolution and crystallization mechanism, the AFt crystallized inwards the pore of hydration product, as shown in figure 1, thus no harmful expansion was expected [3].

Mortar strength of the cement in table 2 showed that the $3 \mathrm{~d}$ strength of the cement was lower than that of P.O 42.5, but 7d and 28d strength was not affected, the $28 \mathrm{~d}$ and $56 \mathrm{~d}$ strength of the SSC 3 was even higher than that of the ordinary portland cement.

Strength of the cement was determined by the quantity of hydration product such as $\mathrm{C}-\mathrm{S}-\mathrm{H}$ and ettringite, which were closely related to hydration reaction.

At early age of the hydration, as the clinker content is relatively low and the hydration of clinker is delayed by gypsum, the early strength is lower. With ongoing of the hydration, more and more $\mathrm{CaO}$ was released, the paste was then in an relative high alkaline environment which promote the dissolution of the slag and release of the $\mathrm{Al}(\mathrm{OH})^{4-}$, in the meanwhile, the concentration of the $\mathrm{Ca}^{2+}$ and $\mathrm{SO}_{4}{ }^{2-}$ increased with dissolution of the fluorogypsun, as a result, the following reaction (eq.1) is accelerated:

$$
6 \mathrm{Ca}^{2+}+2 \mathrm{Al}(\mathrm{OH})_{4}{ }^{-}+4 \mathrm{OH}^{-}+3 \mathrm{SO}_{4}{ }^{2-}+26 \mathrm{H}_{2} \mathrm{O} \rightarrow \mathrm{Ca}_{6}\left[\mathrm{Al}(\mathrm{OH})_{6}\right]_{2} \cdot 3 \mathrm{SO}_{3} \cdot 26 \mathrm{H}_{2} \mathrm{O} \quad 1
$$

In the reaction above, the concentration of the cation and ions in the left side, especially the concentration of $\mathrm{Al}(\mathrm{OH})^{4-}$, controlled the speed and equilibrium of the reaction and quantity of the ettringite as well. The slag had a high reactivity as the high content of $\mathrm{Al}_{2} \mathrm{O}_{3}$ and $\mathrm{CaO}$, this, together with the suitable $\mathrm{pH}$ value of hydration environment, result in the high final strength of the cement mortars.

hydration mechanism of supersulphated cement. Hydration of the low-carbon cement is different from that of portland cement as slag instead of clinker is the major composition. Actually, the activation of slag by alkalineas as well as calcium sulfate is the dominant process for slag hydration.

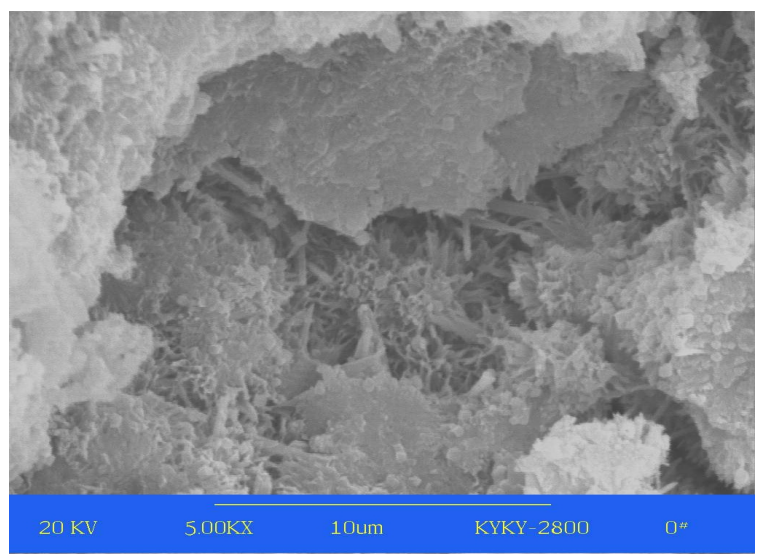

Fig.1 crystallization of $\mathrm{AF}_{\mathrm{t}}$ inwards pore

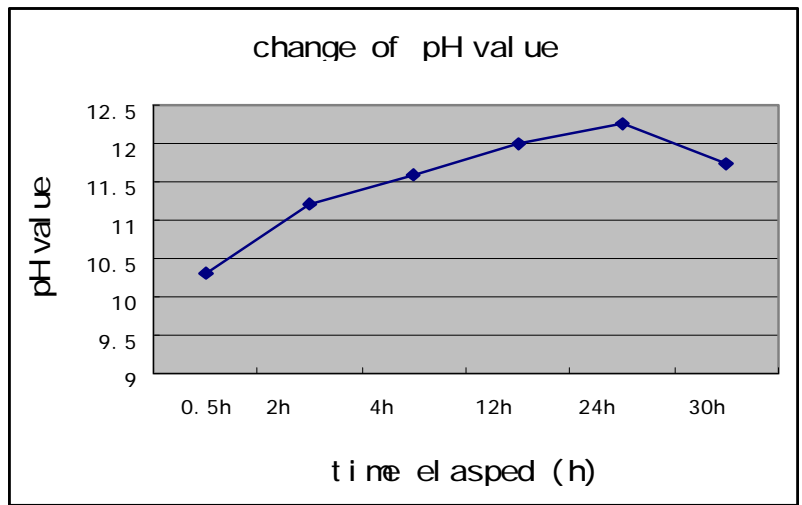

Fig. $2 \mathrm{pH}$ value variation of the paste solution

It is well known that the ground granulated blast furnace slag may be activated by alkaline and sulfate salts, but the mechanisms are different. The former depend on $\mathrm{OH}^{-}$for dissolution of $\mathrm{SiO}_{2}$ and $\mathrm{Al}_{2} \mathrm{O}_{3}$, while the sulfate salts, either $\mathrm{Na}_{2} \mathrm{SO}_{4}$ or $\mathrm{CaSO}_{4}$, promote hydration of slag through $\mathrm{AFt}$ formation as shown in eq. 1 . As the co-exist of $\left[\mathrm{Ca}^{2+}\right]$ and $\left[\mathrm{OH}^{-}\right]$is dominant by solubility product Ksp, so the two mechanisms could not co-exist in harmony.

Furthermore, the formation of ettringite is highly $\mathrm{pH}$ value dependent, paste solution with either high or low alkalinity is not favorable for the reaction.

It is shown in fig. 2 that the alkalinity of this low-carbon cement is a little lower in the first hour, as hydration going on, $\mathrm{pH}$ value increased from initial 10.30 to 12.2 after 24 hours, then there is a decline afterwards. 
As AFt could grow successfully in solution with $\mathrm{pH}$ value ranging from 10.8 to 12.5 , the environment is favorable for the formation of harmless ettringite by through-solution mechanism, which is important for good strength increase of the supersulphated cement stone.

\section{Conclusions}

Low-carbon cement made of $10 \%$ of clinker and $90 \%$ of industrial wastes may get qualified soundness and reasonable 28 day strength, 56 day trength $(63.1 \mathrm{MPa})$ is even higher than the ordinary portland cement $(55.7 \mathrm{MPa})$.

Setting time of the cement is delayed by about 2 hours, $3 \mathrm{~d}$ strength of cement mortar is relative lower.

Formation of ettringite is important for strength development of the low-carbon cement, the $\mathrm{pH}$ value of the cement paste (10.8-12.5) is favorable for ettringte formation.

\section{References}

[1] C.A. Hendriks, E. Worrell, L. Price, N. Martin, et al. Emission reduction of greenhouse gases from the cement industry, Proceedings of the 4th International Conference on Greenhouse Gas Control Technologies, Interlaken, Austria, Aug.30-Sept. 2, IEA GHG R\&D Programme, UK, 1998.

[2] H. Kühl, Verfahren zur Herstellung von Zement aus Hochofenschlacke, German Patent No. 237777, December 23, 1908.

[3]Bryant Mather. Letter to editor: ettringite terminology. Cement and Concrete Research, Volume 26(11), p 1745, 1996. 